\title{
EESTI MURDESÕNA VING
}

\author{
VILJA OJA
}

Annotatsioon. Riista, mille abil seatapu ajaks looma suu suleti, on eesti murretes nimetatud sõnaga ving. Niisugune sulgemisvahend koosnes nöörsilmusest ja pöörast - puupulgast, millega silmus pingule keerati, et takistada looma karjumast ja hammustamast. Rahvakeeles on sellel instrumendil palju nimetusi, nt seaninapöör, prillid, seaprill, ninaprill, ninakeere, nõnapulk, võru, vahr. Enamik nimetusi lähtub riista osadest, nende kujust ja otstarbest. Sõna ving päritolu ega nimetamismotiivi pole tuvastatud. Tõenäoliselt on tegemist laensõnaga. Artiklis käsitletakse võimalike laenuallikatena alamsaksa wind- ja baltisaksa zwingtüvega sõnu.

Võtmesõnad: etümoloogia, laensõna, häälikumuutus, eesti murded, saksa keel

\section{Ving-tüvelised sõnad, nende kasutus, levik ja sünonüüme}

Eestimaal on olnud vanasti (umbes XX saj alguseni) kombeks enne sea tapmist tal suu sulgeda, et takistada looma karjumast ja hammustamast. Sea koonu ümber tõmmati nöörist silmus, mille külge kinnitatud puupulgaga keerati nöör pingule. Rõuge murrakus on selgitatud: kabõl visati t́sialõ ümbre nõna ja pulgaga 'püürtí nõna kińni?. Sellise sulguri nimetus on 1937. aastal ilmunud „Eesti õigekeelsuse-sõnaraamatus“ seaninapöör seletusega 'vahend seatapmisel' (EÕS: 1339). Vanematest sõnaraamatutest ja tänapäeva kirjakeele sõnaraamatutest ei õnnestunud selle asja nimetust leida. Eesti Rahva Muuseumi kogus kasutatakse nimetust sea suuline $\sim$ seasuuline ${ }^{l}$. Juuresolev foto kujutab kirjeldatud eseme üht eksemplari, mille olid Gustav Ränk ja Enn Koit saanud Lääne-Saaremaalt etnograafiliste esemete kogumise retkel 1940. aastal ning mida praegu säilitatakse Eesti Rahva Muuseumis (ERM A 490:77; http://muis.ee/ museaalview/629636).

${ }^{1}$ Murdesõnavara kogus (EMSUKA) on sõna seasuuline üksnes puuvankri detaili nimetusena. 


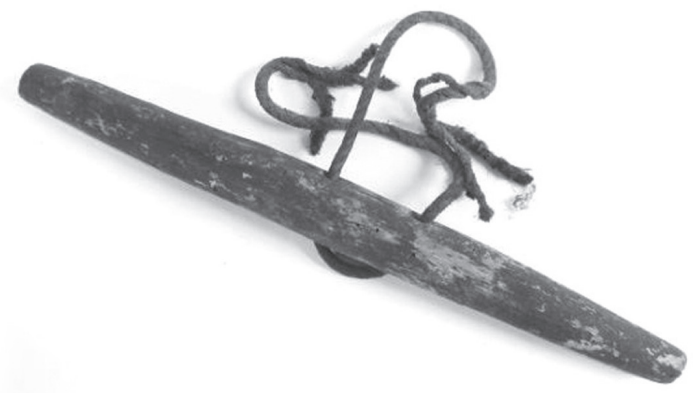

Eesti murretes on seasuu sulgemise vahendit nimetatud mitut moodi. Põhja-Eestis olid kõige ulatuslikumalt levinud nimetus prill(id) ning seda sisaldav liitsõna seaprill(id), kohati ninaprill; Lõuna-Eestis tarvitati enim nimetusi varu või vahr(u) 'võru' ja ving (vt kaart). Ei teki ilmselt küsimust, miks silmusekujulist vahendit kutsuti prill või võru, aga sõna ving nimetamismotiiv pole nii selge. Tänapäeva eesti kirjakeeles väljendab noomen ving kolme mõistet: 'põlemisel erituv gaas; suits; kirbe lehk', 'vihavimm, kius' ja 'vinguv häälitsus' (EKSS: 364). Vana kirjakeele allikais leidub veel Wing G -go '(piitsa)plaks': Piitsa Wing, ja omadussõna wing tähenduses 'vinge': Tuul on wing (nt Vestring 1998: 291). Seasuu sulgemise vahendiga need mõisted ei seostu. Alljärgnevalt tutvustatakse kõnealuse eseme (edaspidi: seasuusulgur) ving-tüvelisi nimetusi ja käsitletakse sõnatüve algupära. Murdeaines pärineb eesti murdesõnavara kogust (EMSUKA) ja murdesõnaraamatutest.

Nimisõna ving g vingu märkis seasuusulgurit peamiselt Võru murdes, nt Urv tetti sääre ving, tuu 'pańti ‘tsialõ `nõnna 'tehti säärane ving, too pandi seale ninna' (KVVE: 385). Mõnes lauses tähistab ving otseselt silmust, nt Krl ving kablanõ, 'puunõ pulk man 'nöörist silmus, puust pulk juures'. Tartu murde alal on ving registreeritud Puhja ja Otepää murrakust, kuid laiemalt oli seal levinud ss-lõpuline vinguss g vingusse (Nõo Kam Ote Rõn), nt Kam vingussega käänäp tsia lõvva 'kinni, et suud ammuli ei saa 'aada. Mõni teade on verbi vingutama 'vinguga sulgema' ja selle põhjal moodustatud nimisõnade vingutuss, vingutuspulk vingutusvõru kohta, nt Nõo vingutuspulk 'olli vassa pikune, sinna keideti kabel kesk ’paika ‘kinni, nii et 'alla jäi kablast võru, vingutusvõru 'vingutuspulk oli vaksa pikkune, sinna seoti nöör keskkohta kinni, nii et alla jäi nöörist võru, vingutusvõru'. 


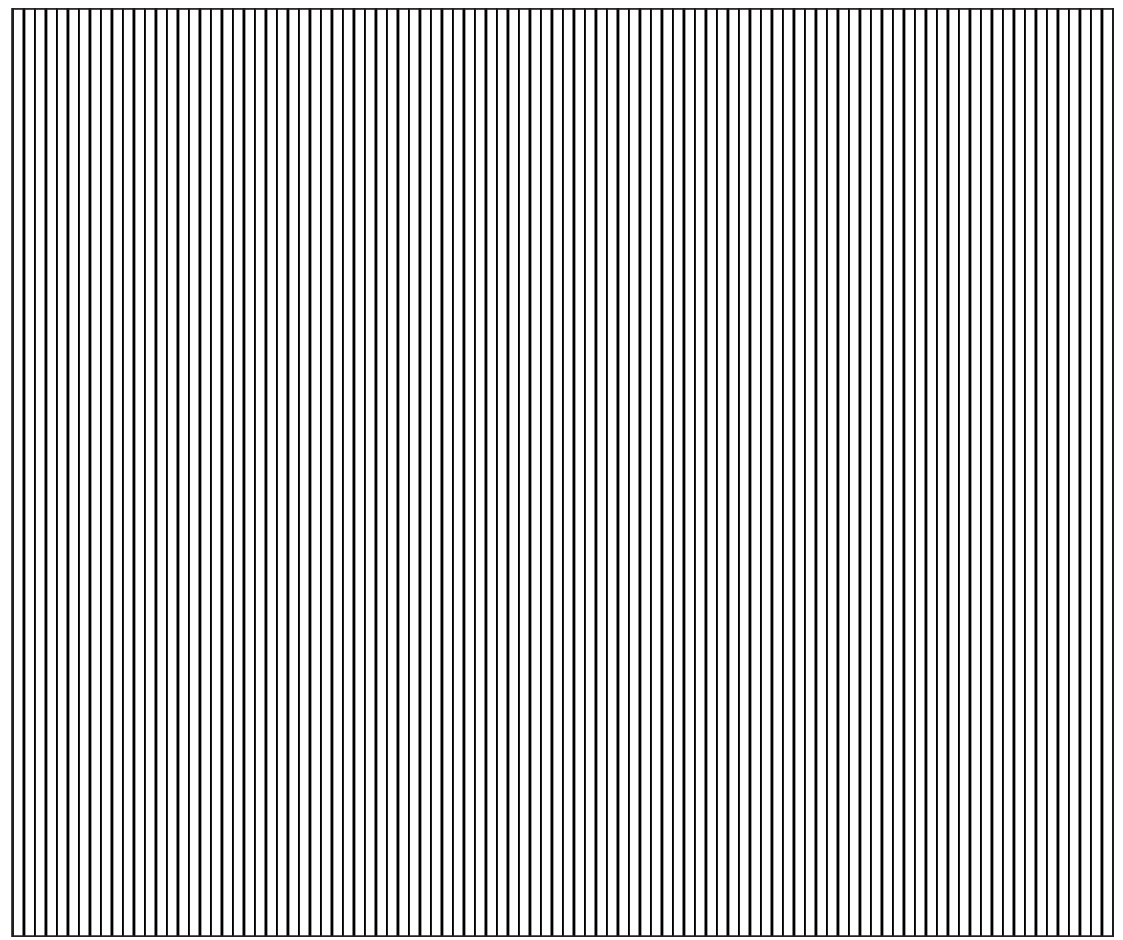

Kaart. Seasuusulguri tuntumate nimetuste levik murretes

Peale Kagu-Eesti on sama tüvega sõnu kasutatud saarte murdes: V11

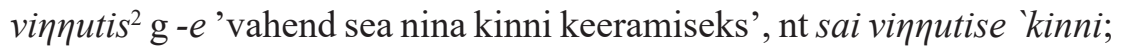

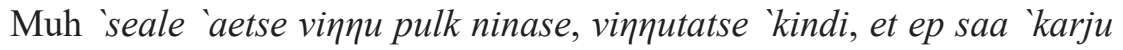

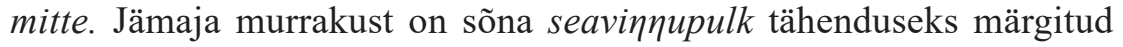
'seasuuline', nagu ka Eesti Rahva Muuseumi kogus.

Kaardilt on näha, et Kagu-Eestis tarvitati vingu-tüvelisi sõnu kõrvuti sünonüümiga $v a h r(u)$. Kambja keelejuhi väitel on sealses murrakus vinguss uuem ja vahr vanem nimetus. Võru murdes on sõna ving kirjakeelne vaste 'silmus' (EVS: 534) ning see on leidnud ka laiemat kasutust kui üksnes seasuu sulgemise vahend, nt võtaq mu auto vingu otsa! 'võta mu auto puksiiri' (Jüva 2002: 530); abiellumise kohta on piltlikult öeldud 'Puulba 'pańti Matilõ ka ving `nõnna Rõu (EMSUKA). Sõnatüve etümoloogia ei ole teada. Kahtlevalt on oletatud, et seasuusulguri nimetus ving võiks

2 Saarte murdes märgib - $\eta \eta$ - häälikuühendi - ng-vastet 2 . vältes. 
lähtuda samast häälitsust imiteerivast onomatopoeetilis-deskriptiivsest tüvest nagu verb vinguma (Koponen 1998: 195). Semantilist aspekti arvestades on neid sõnu omavahel siiski raske seostada. Selle vahendiga ei tekitatud sea (piltikult ka auto või mehe) vingumist, vaid kokku sidudes piirati mingil määral objekti liikumist või tegutsemist. Nimetamismotiivi 'vinguma' välistab ka võrdlus eseme muude nimetustega.

Kõnealuse riista teised teada olevad nimetused on inspireeritud peamiselt selle osadest - silmusest ja pöörafunktsiooniga pulgast: prill, võru ja vahr, (nõna)pulk, pöör (eL püür), Helme murrakus on seasuusulgurit nimetatud vińn, Läänemaal keere, keermes, nt Kul tõmmab seal (= seale) 'keerde nina ’peale (EMSUKA). Tähenduses 'pöör (kinnitus-, veo-, tõsteja pingutusabinõu)' esinevad eesti murretes ka keskalamsaksa keelest laenatud vinn g vinna ( $\mathrm{R}$ vinna, eP M Ran), vińn g vińni (Hää San $\mathrm{V}$ ), vind g vinna (Var Mih) ja võnd g võnnu (Lei) < asks winde (sks Winde) 'vints; pöör' (EEW: 3865; EES: 608; Viikberg 2016). Võru murdes märgib vińn (g vińni) peamiselt veoköit, millega (ka pööra abil) paati või parve kaldale tõmmatakse (EMSUKA). Häälikulisest küljest ja tähenduse poolest on eesti sõnale ving samuti lähedane saksa keeles mõisteid 'pitskruvi; otsavõru, kaitserõngas' märkiv noomen Zwinge. Veendumaks, kas ja kuidas võiks eesti ving seostuda alamsaksa wind- või saksa $z$ wing-tüveliste sõnadega, vaadeldakse nende kasutust veidi põhjalikumalt.

\section{Saksa wind- ja eesti ving}

Verb winden väljendab saksa keeles muu hulgas mõisteid 'painutama, käänama, pöörduma, kõverdama; vingerdama; pinguldama, vinna tõmbama', noomeni winde tähendus oli alamsaksa keeles ka 'käänd, keerd; rõngas, kera; vinn, pöör, vint jm', vrd sks Windung (Grimm 30: 287; Lübben 1993: 584; Kluge 2002: 991; EWD: 1569-1570; WDG: 4358). Martin Lutheri keskülemsaksakeelses tekstis olevat verbi winden sünonüümina kasutatud sõnakuju wingen: „die verstockten mügen sich drehen und wenden, ringen und wingen" 'paadunud peavad tiirlema ja pöörlema, väänlema ja keerlema' (Grimm 30: 285, 337; Behaghel 1928: 360). Rohkem teavet selles tähenduses saksa verbivariandi wingen $(=$ winden) kohta pole. Eesti vanimatest kirjalikest allikatest on Heinrich Gösekeni sõnastikus (1660) verbivariandid winnima, winnuma ja winnoma tähendusega '(vett) 
ammutama, üles tõstma, pumpama' $(324,366)$ ja '(viljakotte jm) ploki abil üles tõstma, vinnama' $(114,472)$ ning winnoma ka tähenduses '(vibu) pingule tõmbama' (386). XVIII saj sõnastikes esitatakse verbi winnama juures need tähendused koos: 'aufwinden, schlenckern' (Helle 1732: 209), 'aufwinden, aufspannen' (Hupel 1780: 313). Wiedemanni sõnaraamat (1869) annab märksõna winnama all ka murdevariandid windama ja wińnima 'spannen, aufziehen, aufwinden' (Wiedemann 1869: 1511, 1973: 1364). Eesti verbi on peetud kas tuletiseks noomenist vinn (vrd vinna tõmbama, vinnas olema) või omaette alamsaksa laenuks (EEW: 3865; Raun 1982: 206; EES: 608; Viikberg 2016). Seega sisu poolest sobiks alamsaksa wind-tüveline sõna eesti ving-tüveliste laenuallikaks. Kahtlusi on võinud tekitada tüveklusiili erinevus.

Eesti keeles leidub muidki sõnu, milles $d$ asemel esineb $g$ või vastupidi, eriti murrete tasandil. Sellisele vaheldusele juhtis tähelepanu juba Lauri Kettunen, nimetades ühe põhjusena klusiili kadu astmevahelduslike sõnade nõrgaastmelistes vormides, nagu peig g peiu, laug g lau, samuti konsonantühendites, nagu $l d: l l$, nd : nn (Kettunen 1917: 8-9, 1929: 35). Nii varieeruvad murdekeeles näiteks sõnad peigmees $\sim$ peidmees, silmalaug silmalaud, seĺgroog seĺgrood seĺgroo säĺlgruuds (vt ALFE: 373-376, 384-387; Neetar 2012). Reeglipäratu häälikuasendus -dl-> -gl- esineb näiteks sõnas hiiglane, murretes iidlane $\sim$ iiglane (hiid $<$ hiis), vrd sm hiitolainen (EMS I: 891, 893; EES: 75). Verbis sõorduma on Mulgi murdes -rd-asemel -rg-: sõõrguma. Vaheldus -nd > -ng esineb sõnas hangeldama, murretes andeldama jm, vrd sks handeln (EMS I: 357; Wiedemann 1869: 36, 40) ja paljudes teistes sõnades (vt Vaba 2016: 253-256).

Laensõnades näib sellises positsioonis $d$ ja $g$ vaheldus mõnel juhul põhinevat püüdlusel mugandada võõras sõna varem tuntu sarnaseks. Näiteks väikese heina- või viljahunniku nimetus saad (g sao, saadu) on Mulgi murdes ja selle naabruses saag (g sae). Suurem varieeruvus esineb harilikult laensõnades. Näiteks sõna pöid 'jala, suka, jalanõu või ratta osa' (alggerm *beuđa-) murdevasted on peid, peüd, pöüg, põud, pöis, pööv. Saksa keelest on laenatud sindel 'soonega katuselauake' ( $<$ (balti) saksa Schindel, vt EEW: 2803; Haak 1990: 353). Eesti murretes on sellest levinud variandid sindli, singel, singli, sinnel, sinner, sinder, sindri ning liitsõnad sindlikatus ja singlikatus, sindlilaud ja singlelaud jt (EMSUKA).

Häälikulise sarnasuse kõrval on analoogiamoodustiste puhul silmas peetud sõnade tähenduse sarnasust, näiteks on omavahel segunenud 
inimese selgroogu, kalaluud, kõrstaimi ja mitmesuguste esemete tugiosi tähistavad sõnad rood, roo, roots, roog. Seasuusulguri nimetuse ving

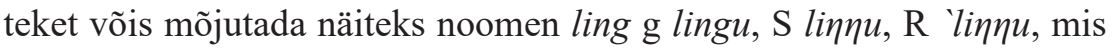
murdeti märgib mõisteid 'ling; silmus; kaevuvinn' (< kasks slinge, sks Schlinge 'silmus') (EEW: 1319; EMS V: 240-241). Tähendusrühma 'pöör, keerama jms' puhul on murdesõnale ving lähedane ka vändaga käsipuuri nimetus Tartu ja Võru murdes: vinger $\mid d^{3}$, -t, - di, vingṍd, vinger(puur), Plv vinger(uherd) < (balti)saksa Wringelbohrer (Wiedemann 1869: 1514; 1973: 1366; Haak 1990: 354; EMSUKA). Häälikuliselt ei sobi puurinimetus seasuusulguri ving aluseks, aga sisuline võrdlus rahva hulgas pole välistatud - eesti keeles on terve hulk rahvaetümoloogia põhjal moonutatud laensõnu.

\section{Saksa zwing- ja eesti ving}

Tänapäeva „Saksa-eesti sõnaraamatus“ on zwing-tüveline nimisõna Zwinge 'kruviriisk ehk pitskruvi [käsitsi reguleeritav kinnitus- ja pingutustööriist tisleritöödel]; otsavõru, kaitserõngas, kaitsetupp', omadussõna zwingend tähenduses 'tungiv, mõjuv, veenev, kindel' ja verb zwingen 'vägivallaga allutama; sundima (millekski); jagu saama' (SES: 1453). Saksa verb zwingen esineb sellisel kujul alates XIV sajandist. Varasemad (kasks, vüsks ja küsks) sõnakujud olid thwingan, dwingan, dwingen, twingan, twingen ning nende vasted teistes germaani keeltes olid järgmised: vanafriisi thwinga, friisi twinge, hollandi dwingen, vanarootsi ja keskrootsi pvinga, rootsi twinga, taani tvinge (Grimm 32: 1225; EWD: 1631). Germaani verbi põhitähendus on olnud 'vägivalda tarvitades mingit keha kokku pressima'. Saksakeelne verb on aja jooksul (VIII-XX saj) väljendanud ka mõisteid 'kokku pigistama, pressima, suruma, ahendama, kitsendama, piirama, ümbritsema, sulustama, sulgu ( lukku) panema, taltsutama, ohjeldama, sundima' (EWD: 1631-1632; WDG: 4545). Keskalamsaksa sõnaraamatus on verbi dwingen tähendused rühmitatud kaheks: 1) sks engen, drücken, pressen 'ahendama, pigistama, (välja) pressima, (kokku) pressima, suruma', 2) sks zwingen 'sundima jm'; nimisõna dwank on seletatud saksa keeles sõnadega Zwang, Gewalt, Nötigung 'sundus, surve;

3 Selline väike vahetatavate teradega puur tuli eesti käsitöönduses kasutusele umbes XV saj ning hiljemalt XVII saj oli juba laialt kasutatav (Viires 1960: 54-57; 2006: $53-55)$. 
võim, vägivald' (Lübben 1993: 90). Võrreldes loetletud tähendusi eesti seasuusulguri otstarbe ja kasutusega, näeme selget semantilist ühisosa, nii et sisu poolest võiks seasuusulguri nimetus ving olla saksa laen.

Wiedemanni sõnaraamatus on kaks ving-tüvelist verbi: wingama (eL) winkama (sks schleudern, schlenkern, werfen 'lingu heitma'), mille sünonüümiks on märgitud vinnama (Wiedemann 1869: 1514; 1973: 1366-1367), ning wingima saksa vastetega zwingen, bedrängen 'sundima, peale käima, välja pressima vms' (Wiedemann 1869: 1514; 1973: 1366). Carl Sallmanni baltisaksa laensõnade käsitluses esineb wingima (= sks zwingen) näitena demonstreerimaks siinsetes baltisaksa laenudes tavapärast häälikumuutust $z w->w$ - [v-] (Sallmann 1880: 22). Nimisõna ving 'seasuusulgur', mis Wiedemanni sõnaraamatus puudub, võib olla kohalik tuletis verbist (varasemas kirjaviisis) wingama või wingima, kuid selle kui uuema laenu doonorsõnaks võib olla ka sks Zwinge. Seasuusulgur täidabki sisuliselt pitskruvi funktsiooni, toimides sellega sarnasel põhimõttel. Kus seda väljaspool Eestit ja kui ulatuslikult seatapul kasutati, pole teada ${ }^{4}$. Tegemist on suhteliselt vähetuntud või vähetähtsa esemega, mistõttu selle nimetust pole ehk peetud vajalikuks sõnaraamatutes esile tuua, nagu see puudub ka enamikust eesti sõnastikest.

\section{Kokkuvõte}

Eelneva analüüsi põhjal saab väita, et seasuusulguri nimetus ving on eesti keelde laenatud sakslastelt, kuid otsest doonorsõna on raske määrata. Ühelt poolt võib laenuallikaks olla saksa noomen Zwinge või verb zwingen, mis on allunud eesti keeles seaduspärasele häälikumuutusele $z w->v$-. Teiselt poolt sobib laenuandjaks alamsaksa verb winden või noomen winde (vrd sks Windung), milles on toimunud eesti keele sõnades puhuti ette tulev, ehkki ebareeglipärane klusiili vaheldus $d>g$. Olemasoleva materjali põhjal näib kahest võimalikust laenuallikast veidi tõenäolisem saksa zwing-tüveline variant, mis oleks häälikuliselt korrektne vaste ja sobiks hilisema laenu staatusega, kuid kindlat otsust praegu teha ei saa.

${ }^{4}$ Küsisin selle eseme nimetusi läti dialektoloogilt, kes aga midagi ei leidnud (korralikku murdesõnade kogu Läti Keele Instituudis pole). 


\section{Kirjandus}

ALFE $=$ Atlas Linguarum Fennicarum. Itämerensuomalainen kielikartasto. Läänemeresoome keeleatlas. Ostseefinnischer Sprachatlas. Лингвистический атлас прибалтийско-финских языков. ALFE 2, 2007. Päätoim. Tuomo Tuomi. 2. osan vastaava toimittaja Tiit-Rein Viitso. Toimitus: Anneli Hänninen, Arvo Laanest, Helmi Neetar, Vilja Oja, Vladimir Rjagojev, Seppo Suhonen, Tuomo Tuomi, Tiit-Rein Viitso, Nina Zaitseva. (= Suomalaisen Kirjallisuuden Seuran Toimituksia 800. Kotimaisten kielten tutkimuskeskuksen julkaisuja 118.) Helsinki: Suomalaisen Kirjallisuuden Seura, Kotimaisten kielten tutkimuskeskus.

Behaghel, Otto 1928 (1891). Geschichte der deutschen Sprache. 5. verb. und stark erw. Aufl. (= Grundriss der germanischen Philologie 3.) BerlinLeipzig: Walter de Gruyter.

EES = Iris Metsmägi, Meeli Sedrik, Sven-Erik Soosaar 2012. Eesti etümoloogiasõnaraamat. Eesti Keele Instituut. Tallinn: Eesti Keele Sihtasutus.

EEW = Julius Mägiste. Estnisches etymologisches Wörterbuch. I-XII, 19821983. Helsinki: Finnisch-Ugrische Gesellschaft.

EKSS = Eesti keele seletav sõnaraamat. 6, 2009. „Eesti kirjakeele seletussõnaraamatu“ 2., täiend. ja parand. tr. Toim. Margit Langemets, Mai Tiits, Tiia Valdre, Leidi Veskis, Ülle Viks, Piret Voll. Eesti Keele Instituut. Tallinn: Eesti Keele Sihtasutus. https://www.eki.ee/dict/ekss/index. cgi?Q=ving\&F=M; http://www.eki.ee/dict/ekss/.

EMS = Eesti murrete sõnaraamat. I-VI, 1994-2017. Eesti Teaduste Akadeemia Eesti Keele Instituut. Tallinn: Eesti Keele Instituut, Eesti Keele Sihtasutus. http://www.eki.ee/dict/ems/; http://www.eki.ee/dict/ems/ems.html.

$\mathbf{E V S}=$ Eesti-võru sõnaraamat. Eesti-võro sõnaraamat. 2014. Koost. Mariko Faster, Laivi Org, Urmas Kalla, Sulev Iva, Triin Iva. Võru Instituut.

EWD = Etymologisches Wörterbuch des Deutschen. 2 (M-Z), 1993. 2. Auflage, durchgesehen und ergänzt von Wolfgang Pfeifer. Berlin: AkademieVerlag.

EÕS = Eesti õigekeelsuse-sõnaraamat. III, 1937. „Eesti keele õigekirjutusesõnaraamatu“ II täiend. ja parand. tr. Tartu: Eesti Kirjanduse Selts.

Grimm = Jacob Grimm, Wilhelm Grimm 1854-1960. Das deutsches Wörterbuch von Jacob und Wilhelm Grimm auf CD-ROM und im Internet. Ein Projekt des Kompetenzzentrums für elektronische Erschließungs- und Publikationsverfahren in den Geisteswissenschaften an der Universität Trier in Verbindung mit der Berlin-Brandenburgischen Akademie der Wissenschaften Berlin. Leipzig: S. Hirzel. http://woerterbuchnetz.de/ DWB/.

Göseken, Heinrich 1660. Manuductio ad Linguam Oesthonicam, Anführung Zur Öhstnischen Sprache, Bestehend nicht alleine in etlichen præceptis 
und observationibus, Sondern auch In Verdolmetschung vieler Teutschen Wörter. Reval: Adolph Simon.

Haak, Anu 1990. Baltisaksa keele kajastusi eesti murrete sõnavaras. - Keel ja Kirjandus 6, 353-355.

Helle, Anton Thor 1732. Kurtzgefasste Anweisung zur Ehstnischen Sprache, in welcher mitgetheilet werden I. Eine Grammatica. II. Ein Vocabularium. III. Proverbia. IV. Ænigmata. V. Colloquia. Halle: Stephan Orban. Faksiimile: http://www.digar.ee/arhiiv/nlib-digar:100071.

Hupel, August Wilhelm 1780. Ehstnische Sprachlehre fuer beide Hauptdialekte, den revalschen und doerptschen; nebst einem vollstaendigen Woerterbuch. Riga, Leipzig: Johann Friedrich Hartknoch. Faksiimile: https:// books.google.ee/books?id=RmIUAAAAQAAJ\&printsec=frontcover\& source $=\&$ redir_esc $=y \& h l=e n \# v=$ onepage $\& q \& \mathrm{f}=$ false.

Hupel, August Wilhelm 1818. Ehstnische Sprachlehre für die beyden Hauptdialekte, den revalschen und dörptschen, nebst einem vollständigen ehstnischen Wörterbuche. Zweyte durchgängig verbesserte und vermehrte Auflage. Mitau: J. F. Steffenhagen und Sohn.

Jüva, Sullõv 2002. Võro-eesti synaraamat.Võru-eesti sõnaraamat. (= Võro Instituudi Toimõndusõq 12.) Võru: Võro Instituut. http://www.folklore. ee/Synaraamat/v.html.

Kettunen, Lauri 1917. Viron kielen äännehistorian pääpiirteet. (= Suomalaisen Kirjallisuuden Seuran toimituksia 156.) Helsinki: Suomalaisen Kirjallisuuden Seura.

Kettunen, Lauri 1929. Eestin kielen äännehistoria. 2. uusittu painos. (= Suomalaisen Kirjallisuuden Seuran toimituksia 156.) Helsinki: Suomalaisen Kirjallisuuden Seura.

Kluge, Friedrich 2002. Etymologisches Wörterbuch der deutschen Sprache. 24., durchgesehene und erweiterte Auflage, bearbeitet von Elmar Seebold. Berlin - New York: Walter de Gruyter.

Koponen, Eino 1998. Eteläviron murteen sanaston alkuperä. Itämerensuomalaista etymologiaa. (= Suomalais-Ugrilaisen Seuran Toimituksia 230.) Helsinki: Suomalais-Ugrilainen Seura.

KVVE = Kuiss vanal Võromaal eleti. 2005. Toim. Helju Kaal, Mari Must, Eevi Ross. (= Valimik korrespondentide murdetekste VI.) Tallinn: Eesti Teaduste Akadeemia Emakeele Selts.

Lübben, August 1993 (1888). Mittelniederdeutsches Wörterbuch. Nach dem tode des Verfassers Vollendet von Christoph Walther. Darmstadt: Wissenschaftliche Buchgesellscheft (Reprografischer nachdruck der Ausg. Norden und Leipzig, 1988). 
Neetar, Helmi 2012. Kehaosade nimetustest läänemeresoome keeleatlases. Emakeele Seltsi aastaraamat 57 (2011). Peatoim. Mati Erelt. Tallinn: Teaduste Akadeemia Kirjastus, 103-116.

Raun, Alo 1982. Eesti keele etümoloogiline teatmik. Rooma - Toronto: Maarjamaa.

Sallmann, Carl 1880. Neue Beiträge zur deutschen Mundart in estland. Reval: Verlag von Franz Kluge. http://www.digar.ee/arhiiv/nlib-digar:14481.

SES = Elisabeth Kibbermann, Salme Kirotar, Paula Koppel 2007. Saksa-eesti sõnaraamat. Deutsch-estnisches Wörterbuch. Toim. ja täiend. Anne Arold, Mari Tarvas, Mari-Ann Palm. Tallinn: Valgus.

Vaba, Lembit 2016. Alternatiivseid etümoloogiaid II. - Emakeele Seltsi aastaraamat 61 (2015). Peatoim. Mati Erelt. Tallinn: Teaduste Akadeemia Kirjastus, 253-261. doi:10.3176/esa61.12.

Vestring, Salomo Heinrich 1998 (1730). Lexicon Esthonico Germanicum. Tartu: Eesti Kirjandusmuuseum.

Viikberg, Jüri 2016. Alamsaksa laensõnad eesti keeles. Veebisõnastik. Eesti Keele Instituut. Tallinn. http://portaal.eki.ee/dict/als/.

Viires, Ants 1960. Eesti rahvapärane puutööndus. Ajalooline ülevaade. Eesti NSV Teaduste Akadeemia, Ajaloo Instituut. Tallinn: Eesti Riiklik Kirjastus.

Viires, Ants 2006. Eesti rahvapärane puutööndus. Ajalooline ülevaade. 2. tr. Tallinn: Ilo.

VMS = Väike murdesõnastik. II, 1989. Toim. Valdek Pall. Koost. Anu Haak, Evi Juhkam, Marja Kallasmaa, Ann Kask, Ellen Niit, Piret Norvik, Vilja Oja, Aldi Sepp, Jaak Simm, Jüri Viikberg. Eesti NSV Teaduste Akadeemia. Keele ja Kirjanduse Instituut. Tallinn: Valgus.

WDG = Wörterbuch der deutschen Gegenwartssprache. 6, 1976-1977. Hrsg. Ruth Klappenbach und Wolfgang Steinitz. Bearbeiter: G. Kempcke, R. Klappenbach, H. Malige-Klappenbach. Akademie der Wissenschaften der DDR Zentralinstitut für Sprachwissenschaft. Berlin: Akademie-Verlag.

Wiedemann, Ferdinand Johann 1869. Ehstnisch-deutsches Wörterbuch. St. Petersburg. https://books.google.ee/books/reader?id=ycARAQ AAMAAJ\&printsec $=$ frontcover\&output $=$ reader\&source $=$ gbs_atb_ hover\&pg=GBS.PP5.

Wiedemann, Ferdinand Johann 1973 (1893). Eesti-saksa sõnaraamat. Neljas, muutmata trükk teisest, Jakob Hurda redigeeritud väljaandest. Tallinn: Valgus.

\section{Sõnavarakogud}

EMSUKA $=$ Eesti murrete ja soome-ugri keelte arhiiv Tallinnas Eesti Keele Instituudis. 


\title{
The Estonian dialect word ving
}

\author{
VILJA OJA
}

While slaughtering pigs, in olden times Estonians have closed the animal's mouth using a string noose, put around the pig's snout and tightened with a wooden toggle. This prevented the pig from shrieking or biting. This tool has been named in the vernacular mostly according to one of the two parts (either the noose or the toggle), e.g. seaninapöör 'pig snout toggle' nõnapulk 'snout stick', seaprill, -prillid 'pig eyeglass(es)', ninaprill 'snout eyeglasses', vahr 'hoop', and others. In south-eastern Estonia, as well as occasionally in the Islands dialect, this object is called ving, vinguss or similar, and a verb formed from the same stem has been used as well. The use of a word with the stem ving in this sort of meaning cannot be justified on the basis of the Estonian word stock and its origin is unknown. In this article, two possible loan etymologies for the Estonian ving stem are presented. First, the loan source may be the German noun Zwinge, which has emerged as ving in Estonian through the regular sound change $z w->v$ - Alternatively, the source word may be the Low German verb winden or the noun winde (cf. German Windung), with the sound change $d>g$, found in other Estonian words as well.

Keywords: etymology, loan words, sound change, Estonian dialects, German language

Vilja Oja

eesti keele ajaloo, murrete ja soome-ugri keelte osakond

Eesti Keele Instituut

Roosikrantsi 6

10119 Tallinn

Vilja.Oja@eki.ee 